\title{
Utility of BID Administration of Cimetidine for Gastric Ulcer : A Comparison with QID Administration in a Double Blind Manner
}

\author{
Shigeru Asaki, Yoshio Goto and Tsuneo Tanaka* \\ The Third Department of Internal Medicine, Tohoku \\ University School of Medicine, Sendai 980 and *School of \\ Health Science, Faculty of Medicine, University of Tokyo, \\ Tokyo 113
}

\begin{abstract}
Asaki, S., Goto, Y. and Tanaka, T. Utility of BID Administration of Cimetidine for Gastric Ulcer: A Comparison with QID Administration in a Double Blind Manner. Tohoku J. exp. Med., 1986, 150 (3), 287-297— The clinical efficacy of cimetidine for gastric ulcer was compared between the standard administration methods in Japan ; $200 \mathrm{mg}$ four times daily and $400 \mathrm{mg}$ twice daily after breakfast and at bedtime in a double blind manner. It was found that the results obtained by $200 \mathrm{mg}$ twice-daily administration were almost comparable to those obtained by the four-times-daily administration without statistically significant difference for healing rate, final global improvement in subjective and objective symptoms, incidence of adverse reactions and effects on laboratory tests. These findings resulted in that the twice-daily administration of cimetidine provides convenience for patients.— cimetidine; BID administration; QID administration; gastric ulcer
\end{abstract}

Cimetidine, a histamine $\mathrm{H}_{2}$ receptor antagonist, is highly effective in the treatment of peptic ulcers and ulcers associated with Zollinger-Ellison syndrome as well as in gastrointestinal hemostasis.

Usually in European countries $200 \mathrm{mg}$ per dose of cimetidine is administered after meals and $400 \mathrm{mg}$ at bedtime, whereas in the United States $300 \mathrm{mg}$ per dose after each meal and at bedtime. In Japan, cimetidine is generally admisistered at $200 \mathrm{mg}$ per dose 4 times daily as suggested by Miyoshi et al. (1980). This protocol is based on a study on the inhibitory effect on nocturnal gastric acid secretion (Miyoshi et al. 1979).

Recently, in many European countries cimetidine $400 \mathrm{mg}$ twice daily administration, after breakfast and at bedtime, has been evaluated. Burland et al. (1980) reported that a single dose of $400 \mathrm{mg}$ after breakfast was almost comparable to $200 \mathrm{mg}$ three times a day after meals for inhibition of gastric acid secretion. Moreover, Blackwood and Northfield (1977) reported that administration of 300 to

Received March 9, 1985; accepted for publication October 23, 1986. 
TABLE 1. List of institutions and researchers having collaborated for the present study

Kazubumi Muranaka, ${ }^{1}$ Yukio Kanazawa, ${ }^{1}$ Akira Kumagai, ${ }^{1}$ Koji Torihata, ${ }^{2}$ Osamu Sato, ${ }^{3}$ Mitsuru Ono, ${ }^{3}$ Yoko Ishikawa, ${ }^{3}$ Fumiyuki Kooka, ${ }^{3}$ Shoji Goto, ${ }^{3}$ Tetsuro Onodera, ${ }^{4}$ Tatsuo Nakajima, ${ }^{4}$ Tadaoki Sugawara, ${ }^{5}$ Suguru Sugawara,,${ }^{5}$ Nobuo Nomura, ${ }^{5}$ Kazuichi Sato, ${ }^{6}$ Masayoshi Sasaki, ${ }^{6}$ Hideo Yamazaki, ${ }^{6}$ Naoaki Tanno, ${ }^{6}$ Norihiko Moriai, ${ }^{6}$ Kanji Komatsu, ${ }^{6}$ Tadashi Hagiwara, ${ }^{7}$ Tatsuya Matsushita, ${ }^{7}$ Yutaka Miyazaki, ${ }^{7}$ Taihei Murakami, ${ }^{7}$ Hisashi Hirakawa, ${ }^{7}$ Shunji Ohkubo, ${ }^{7}$ Harumi Ooizumi, ${ }^{8}$ Akihiro Furusawa, ${ }^{8}$ Tadakazu Matsuda, ${ }^{8}$ Shogo Mito,${ }^{8}$ Kiyoshi Unno, ${ }^{8}$ Akira Atsumi, ${ }^{8}$ Shingo Miyazaki, ${ }^{9}$ Kazuyoshi Itasaka, ${ }^{9}$ Yoshio Chinen, ${ }^{10}$ Mitsuo Takahashi, ${ }^{10}$ Tsuneaki Sato, ${ }^{11}$ Akira Unoura, ${ }^{11}$ Akira Watanabe, ${ }^{11}$ Reiji Yamaya, ${ }^{12}$ Hiroko Ebina,,${ }^{13}$ Ken Horigome,,${ }^{13}$ Hiroyuki Sakurada, ${ }^{14}$ Katsuaki Sato, ${ }^{15}$ Kenichi Yamada, ${ }^{15}$ Hiroyasu Kitaoka, ${ }^{15}$ Kiyomi Miura, ${ }^{15}$ Hirokatsu Kumada, ${ }^{16}$ Yasuo Nagasaki, ${ }^{16}$ Junjiro Onodera, ${ }^{16}$ Suguru Ikeda,,${ }^{17}$ Shoichiro Itoh, ${ }^{17}$ Fukuji Mochizuki, ${ }^{17}$ Masanori Mita, ${ }^{18}$ Tadashi Taima, ${ }^{18}$ Atsushi Takayama, ${ }^{19}$ Hideyuki Sato, ${ }^{19}$ Yoshihide Umezu, ${ }^{19}$ Kozo Ohnami, ${ }^{19}$ Nozomi Itoh, ${ }^{19}$ Teruo Miyamori, ${ }^{19}$ Masamichi Chiba, ${ }^{20}$ Tetsutaro Takeda, ${ }^{21}$ Jun Yamagata, ${ }^{22}$ Akira Sato, ${ }^{23}$ Masayoshi Kobayashi, ${ }^{24}$ Yoshinori $\mathrm{Ra}^{24}{ }^{24}$ Yutaka Kobayashi, ${ }^{24}$ Naoshiro Kimura, ${ }^{24}$ Tatsuo Ueno, ${ }^{25}$ Fujio Saito, ${ }^{25}$ Masaaki Miyano, ${ }^{26}$ Kenichi Shoji, ${ }^{26}$ Hitoshi Kikuchi, ${ }^{27}$ Takeaki Sakai, ${ }^{28}$ Kengoro Matsumoto, ${ }^{29}$ Yoshio Satoh, ${ }^{30}$ Hidetake Kitamura, ${ }^{31}$ Yuta Hosoya,${ }^{32}$ Ikuya Saito, ${ }^{33}$ Yoshiki Sugai, ${ }^{33}$ Hideji Hoshino,${ }^{33}$ Takehiko Shoji, ${ }^{33}$ Koji Funada, ${ }^{34}$ Masaya Takeuchi, ${ }^{34}$ Tetsuo Takeuchi, ${ }^{35}$ Seiichi Arai, ${ }^{35}$ Mitsuo Ohara, ${ }^{35}$ Wataru Kuchiki, ${ }^{36}$ Norio Iwama, ${ }^{37}$ Hiroshi Shishido, ${ }^{38}$ Shuichi Ohara, ${ }^{38}$ Hiroshi Sato, ${ }^{38}$ Daisuke Shibuya, ${ }^{38}$ Toshiki Ohkata, ${ }^{38}$ Yukihiro Ogitsu, ${ }^{38}$ Noriaki Kanazawa, ${ }^{38}$ Katsuhisa Sato, ${ }^{38}$ Hiroshi Hatayama, ${ }^{38}$ Kiyoaki Hanzawa, ${ }^{38}$ Akira Sato, ${ }^{38}$ Michinori Sato, ${ }^{38}$ Toshiaki Nishimura, ${ }^{38}$ and Shuichi Iwai. ${ }^{38}$

1 Towada Shiritsu Chuo Hospital

${ }^{2}$ Hachinohe Shiritsu Shimin Hospital

${ }^{3}$ Iwate Kenritsu Chuo Hospital

${ }^{4}$ Mizusawa Shiritsu Kokuho Hospital

${ }^{5}$ Iwate Kenritsu Iwai Hospital

${ }^{6}$ Yuri Kumiai Sogo Hospital

${ }^{7}$ Hiraga Sogo Hospital

${ }^{8}$ Yamagata Kenritsu Chuo Hospital

9 Yamagata Shiritsu Saiseikan Hospital

${ }^{10}$ Yonezawa Shiritsu Hospital

11 Kokuritsu Sendai Hospital

12 Sendai Sekijuji Hospital

${ }_{13}$ Sendai Tetsudo Hospital

${ }_{14}$ Sendai Shiritsu Hospital

${ }_{15}$ Miyagi Daiichi Hospital

${ }^{16}$ Miyagi Daini Hospital

17 Sendai Iryo Center Hospital

18 Tohoku Rosai Hospital

19 Koritsu Katta Hospital

${ }^{20}$ Choritsu Oogawara Hospital
${ }^{21}$ Miyagi Seijinbyo Center

${ }^{22}$ Miyagi Chuo Hospital

${ }^{23}$ Tohoku Teishin Hospital

${ }^{24}$ Shiogama Shiritsu Hospital

${ }^{25}$ Koritsu Sanuma Hospital

${ }^{26}$ Koritsu Tsukidate Hospital

${ }_{27}$ Koritsu Kesenuma Hospital

${ }^{28}$ Ishinomaki Nisseki Hospital

${ }^{29}$ Koritsu Maiya Hospital

${ }^{30}$ Yoneyama Choritsu Hospital

${ }^{31}$ Kurikoma Choritsu Hospital

${ }^{32}$ Shirakawa Kosei Hospital

${ }^{33}$ Iwaki Kyoritsu Hospital

${ }^{34}$ Shiritsu Joban Hospital

${ }^{35}$ Ohara Sogo Hospital

${ }^{36}$ Koritsu Fujita Hospital

${ }^{37}$ Hanawa Kosei Hospital

38 Third Department of Internal Medicine, Tohoku University 
$400 \mathrm{mg}$ at bedtime could inhibit nocturnal acid secretion completely.

From these points of view, we performed a double blind study to compare the clinical efficacy of cimetidine between QID treatment with $200 \mathrm{mg}$ per dose and BID treatment with $400 \mathrm{mg}$ per dose for gastric ulcer in 38 medical institutions in the Tohoku District, Japan. Table 1 shows the collaborative institutions and researchers for this study. The present paper describes the results obtained from this study.

\section{Materials}

Patients with gastric ulcer endoscopically diagnosed in the 38 institutions in Tohoku area during the period from September, 1981 to February, 1982 were selected for the present study. The severity of the ulcers ranged from stages $\mathrm{A}_{1}$ to $\mathrm{H}_{1}$. Included were round single ulcers (including oval ones) with a diameter of $5 \mathrm{~mm}$ or larger. The patients were aged between 18 and 70 years.

Patients having serious underlying diseases, patients with history of vagotomy or gastrectomy and women who were or might be pregnant were excluded.

\section{Test drugs}

White colored and pink colored tablets, both of which contained $200 \mathrm{mg}$ of cimetidine respectively, were used.

\section{Method of admisistration}

The drug were administered by a double dummy method. Two white colored tablets of cimetidine (or their placebo) were administered orally twice daily (after breakfast and at bedtime), and 1 pink colored tablet (or their placebo) were given orally at four times daily (after each meal and at bedtime). For both regimens, the total daily dose of cimetidine was $800 \mathrm{mg}$.

The treatment continued for 8 weeks. When the ulcer was healed before in course of administration, the administration was discontinued according to the judgement of a doctor.

Other drugs such as anti-ulcer drugs, anti-cholinergic agents, antacids and analgesics were recorded in detail, when used concomitantly.

The endoscopic examination was performed before, and at 4 and 8 weeks of administration to evaluate the healing process.

Observations were made as to the following subjective symptoms: epigastric pain (postprandial, hungertime, nocturnal, not related to feeding), nausea, vomiting, fullness, anorexia, heart burn and belching. These symptoms were evaluated before, and after 1,2, 3 and 4 weeks of administration and classified on a 4-point scales according to severity of symptoms.

\section{Laboratory tests}

Before and after the administration period, the following laboratory tests were performed : hematological tests (red blood cell count, hemoglobin level, hematocrit value, white blood cell count, and platelet count), blood biochemical studies (cholesterol, total protein, $\mathrm{A} / \mathrm{G}$ ratio, GOT, GPT, alkaline phosphatase $(\mathrm{A} 1-\mathrm{P})$, bilirubin, uric acid, BUN, creatinine, $\mathrm{Fe}$ and blood electrolytes $(\mathrm{Na}, \mathrm{K}$ and $\mathrm{Cl}$ ), urinary tests (sugar, albumin, urobilinogen and sediment), pulse rate, blood pressure and ECG.

\section{Adverse reactions}

Written records of any adverse reactions, the severity of symptoms, the clinical course and specific treatment required were described and the relation with the test drug was 
evaluated.

\section{Evaluation of efficacy}

Endoscopic examinations were performed after 4 and 8 weeks of administration. Compared with the pretreatment stage, the ulcer was judged by endoscopy by the following five stages: healed, remarkable shrinkage, slight shrinkage, no change and aggravation. Healing of ulcer was defined in this study as disappearance of white coat by endoscopy.

Improvement of subjective and objective symptoms was rated five stages : remarkable impovement, moderate improvement, slight improvement, no change and aggravation.

Overall improvement from changes in subjective and objective symptoms and endoscopic findings was evaluated by five stages: remarkable improvement, moderate improvement, slight improvement, no change and aggravation.

Overall safety considering the severity and clinical course of side effects and laboratory test results as well as their effects on continuance of administration of drugs was evaluated by four stages: no adverse reactions, slight, moderate and serious adverse reactions.

Utility, taking into accout all of the above ratings, was evaluated by five stages : very useful, useful, slightly useful, doubtful and useless.

Discontinuation of the test drug was determined during the course of the administration when ulcer was judged as healed, when continuance of the trial was judged as impossible by the doctor because of aggravation of existing symptoms or development of serious side effects, or when patients requested so.

\section{Handling of data}

The data of all cases were reviewed by a committee after completion of the trial but before opening the key code.

Statistical analysis

To compare groups given cimetidine twice daily (referred to as BID group) and those given cimetidine four times daily (referred to as QID group) in terms of background factors, $\chi^{2}$ test or Fisher's direct probability estimation was used. Mann-Whitney U-test or Fisher's direct probability estimation was used to compare the efficacy. Significance was set at $p<$ 0.05 .

\section{Results}

\section{Cases included in analysis}

A total of 139 cases was included in the present clinical study. After opening the key code for the double blind study, it was found that the BID group included 70 cases and the QID group 69 cases (Table 2).

Before opening the key code, 19 cases (10 cases of the BID group and 9 cases of the QID group) were excluded from analysis for before-mentioned reasons. Among the remaining 60 cases of BID group and 60 cases of QID group, 2 cases of each group were again excluded from analysis of the final global assessment or efficacy due to the lack of endoscopic data at 8 th week. At the consultation held before opening the key code, it was decided that patients aged over 70 years should be included in special group for the elder patients, and that patients aged less than 18 years should be excluded if their body weight was not more than 30 $\mathrm{Kg}$. However, for the evaluation of safety, the cases excluded from analysis were also included. 
TABLe 2. Subject

\begin{tabular}{clcc}
\hline & & \multicolumn{2}{c}{ Method of administration } \\
\cline { 3 - 4 } & & BID & QID \\
\hline $\begin{array}{c}\text { Cases included } \\
\text { in analysis }\end{array}$ & $\begin{array}{l}\text { Completely employed cases } \\
\text { Dropout cases } \\
\text { (Partially employed) }\end{array}$ & 58 & 58 \\
$\begin{array}{c}\text { Cases excluded } \\
\text { of analysis }\end{array}$ & & 10 & 2 \\
Total & 70 & 9 \\
Test & & & 69 \\
& & & N.S. \\
\hline
\end{tabular}

\section{Background factors}

The two groups were compared as to sex, age, duration of the ulcer symptoms, characterstics of the ulcer (ulcer history, location, shape, size, depth and stage), and the complicating disease. No differences were seen between the BID group and the QID group except in the shape of ulcer. The shape classified as round or oval, showed a significant difference $(p<0.05)$.

Improvement in subjective and objective symptoms

Among the 56 cases of the BID group excluding asymptomatic cases, the final improvement rates were: remarkable improvement, 37 cases $(66.1 \%)$; moderate imporvement, 14 cases $(25.0 \%)$; and slight improvement, 5 cases $(8.9 \%)$. The corresponding figures obtained for 56 cases of the QID group were 36 cases $(64.3 \%), 15$ cases $(26.8 \%)$ and 5 cases $(8.9 \%)$, respectively. Thus, no significant difference was observed between the two groups.

\section{Overall improvement rate}

The overall improvement rate of the 58 cases of the BID group was remarkable, 44 cases $(75.9 \%)$; moderate, 11 cases $(19.0 \%)$; and slight improvement, 3 cases $(5.2 \%)$. In contrast, the rate for the 58 cases of the QID group was remarkable improvement, 42 cases $(72.4 \%)$; moderate improvement, 13 cases $(22.4 \%)$; slight improvement, 2 cases $(3.4 \%)$; and no change, 1 case $(1.7 \%)$. There was no significant difference in overall improvement rate between the two groups.

\section{Overall safety rate}

Out of the 69 cases of the BID group no adverse reactions were observed in 65 cases $(94.2 \%)$. Some form of adverse reactions developed in the remaining 4 cases $(5.7 \%)$, and in 1 case $(1.4 \%)$ the administration of the test drug was discontinued. In 64 cases $(92.8 \%)$ out of the 69 cases of the QID group, no adverse reactions developed, whereas the remaining 5 cases $(7.2 \%)$ experienced some form of adverse reactions. No case of the QID group required discontinua- 
tion of the test drug attributable to adverse reactions. No significant difference was found in overall safety rate between the two groups.

Adverse reactions will be described later in detail.

\section{Utility rate}

The utility was rated as very useful for 37 cases $(63.8 \%)$, useful for 14 cases $(24.1 \%)$ and slightly useful for 7 cases $(12.1 \%)$ out of 58 cases of the BID group. In the QID group it was rated as very useful for 39 cases $(67.2 \%)$, useful for 15 cases $(25.9 \%)$, slightly useful for 3 cases $(5.2 \%)$ and useless for 1 case $(1.7 \%)$. No statistically significant difference was present between the two groups.

\section{Judgement by endoscopic examination (Table 3)}

The improvement rate was calculated by combining number of healed cases and those with remarkable shrinkage. Improvement was seen in 48 of 59 cases $(81.4 \%)$ in the BID group, and 45 of 53 cases $(84.9 \%)$ in the QID group at 4 th week, and in 54 of 58 cases $(93.1 \%)$ in the BID group and 56 of 58 cases $(96.5 \%)$ in the QID group at 8th week. At both assessment periods, no significant difference was found between the BID group and the QID group.

Similar to the improvement rate, no significant difference in the healing rate was found between the BID and the QID groups. Ulcer healing was obtained in 21 of 59 cases $(35.6 \%)$ in the BID group and in 19 of 52 cases in the QID group at 4 th week, and in 48 of 58 cases $(82.8 \%)$ for the BID group and 43 of 58 cases $(74.1 \%)$ for the QID group at 8 th week (Fig. 1).

Changes in subjective and objective symptoms

Changes in subjective and objective symptoms were, as shown in Table 4, expressed by the disappearance rate (cumulative) of symptoms comparing to symptoms before administration.

Significant difference between the BID and QID groups was observed only for postprandial pain after 2 weeks $(p<0.05)$, fasting pain after 1 week $(p<0.05)$ and 2 weeks $(p<0.01)$ and nocturnal epigastric pain after 2 weeks $(p<0.05)$. For all

TABLE 3. Ulcer healing judged by endoscopy

\begin{tabular}{ccccccc}
\hline \multirow{2}{*}{\begin{tabular}{c} 
Time of $\begin{array}{c}\text { Timation } \\
\text { (week) }\end{array}$ \\
\multirow{2}{*}{4}
\end{tabular}} & $\begin{array}{c}\text { Method of } \\
\text { adminis- } \\
\text { tration }\end{array}$ & Healed & $\begin{array}{c}\text { Remarkable } \\
\text { shinkage }\end{array}$ & $\begin{array}{c}\text { Slight } \\
\text { shinkage }\end{array}$ & $\begin{array}{c}\text { No } \\
\text { change }\end{array}$ & Total \\
\cline { 2 - 6 } & BID & $21(35.6)$ & $27(45.8)$ & $10(16.9)$ & $1(1.7)$ & 59 \\
\hline 8 & QID & $19(35.8)$ & $26(49.1)$ & $7(13.2)$ & $1(1.9)$ & 53 \\
\hline & BID & $48(82.8)$ & $6(10.3)$ & $4(6.9)$ & 58 \\
\hline
\end{tabular}

$(\quad): \%$ 
Fig. 1. Healing rate judged by endoscopy. $\circ$ QID ; •, BID.

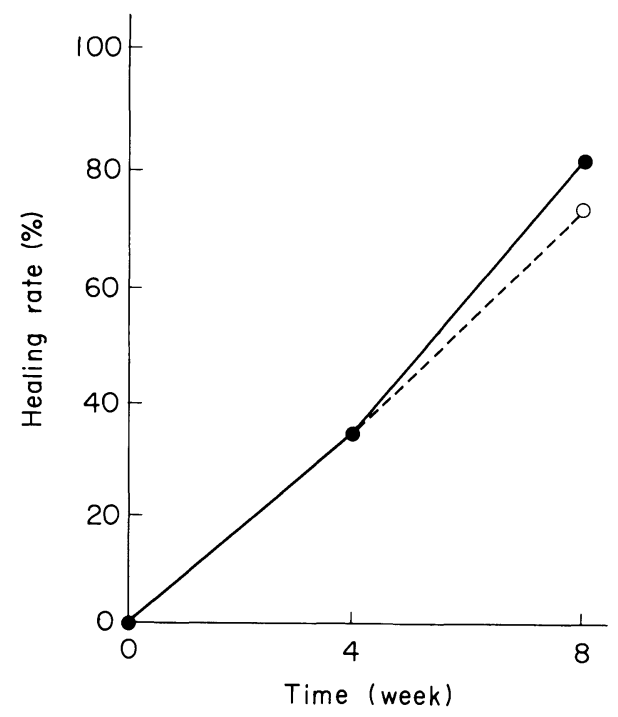

TABLE 4. Disappearance rate of symptoms

\begin{tabular}{|c|c|c|c|c|c|c|c|c|c|}
\hline \multirow{3}{*}{$\begin{array}{l}\text { Epigas- } \\
\text { tric pain }\end{array}$} & \multirow{3}{*}{$\begin{array}{l}\text { Method } \\
\text { of } \\
\text { adminis- } \\
\text { tration }\end{array}$} & \multicolumn{8}{|c|}{ Clinical course (week) } \\
\hline & & \multicolumn{2}{|c|}{1} & \multicolumn{2}{|c|}{2} & \multicolumn{2}{|c|}{3} & \multicolumn{2}{|c|}{4} \\
\hline & & $\begin{array}{l}\text { Disap- } \\
\text { pearing } \\
\text { rate }\end{array}$ & Test & $\begin{array}{l}\text { Disap- } \\
\text { pearing } \\
\text { rate }\end{array}$ & Test & $\begin{array}{l}\text { Disap- } \\
\text { pearing } \\
\text { rate }\end{array}$ & Test & $\begin{array}{l}\text { Disap- } \\
\text { pearing } \\
\text { rate }\end{array}$ & Test \\
\hline \multirow{2}{*}{$\begin{array}{l}\text { Post- } \\
\text { prandial }\end{array}$} & BID & 40.0 & \multirow{2}{*}{ N.S. } & 66.7 & \multirow{2}{*}{$p<0.05$} & 86.7 & \multirow{2}{*}{ N.S. } & 93.3 & \multirow{2}{*}{ N.S. } \\
\hline & QID & 63.2 & & 100 & & 100 & & 100 & \\
\hline \multirow{2}{*}{$\begin{array}{l}\text { Hunger } \\
\text { time }\end{array}$} & BID & 40.0 & \multirow{2}{*}{$p<0.05$} & 68.6 & \multirow{2}{*}{$p<0.01$} & 82.9 & \multirow{2}{*}{ N.S. } & 91.4 & \multirow{2}{*}{ N.S. } \\
\hline & QID & 67.7 & & 96.8 & & 96.8 & & 100 & \\
\hline \multirow{2}{*}{$\begin{array}{l}\text { Noc- } \\
\text { turnal }\end{array}$} & BID & 44.0 & \multirow{2}{*}{ N.S. } & 72.0 & \multirow{2}{*}{$p<0.05$} & 88.0 & \multirow{2}{*}{ N.S. } & 92.0 & \multirow{2}{*}{ N.S. } \\
\hline & QID & 52.2 & & 95.7 & & 100 & & & \\
\hline \multirow{2}{*}{$\begin{array}{l}\text { Not } \\
\text { related } \\
\text { to food }\end{array}$} & BID & 57.1 & \multirow{2}{*}{ N.S. } & 64.3 & \multirow{2}{*}{ N.S. } & 71.4 & \multirow{2}{*}{ N.S. } & 85.7 & \multirow{2}{*}{ N.S. } \\
\hline & QID & 72.2 & & 88.9 & & 84.4 & & 94.4 & \\
\hline
\end{tabular}

of these items higher disappearance rates were recorded for the QID group. As for other items however, no significant difference was seen between the two groups at any of the evaluation time.

Ulcer healing rate stratified by background factors

At both evaluation periods (at the 4 th week and 8 th week) the healing rate of ulcer stratified by each background factor was similar for the BID and the QID groups, without significant difference. 


\section{Adverse reactions}

The symptoms reported by patients, and clinical courses are shown in Table 5 . As shown in the table, adverse reactions developed in 4 cases of the BID group; 2 cases of constipation and 1 case of poor appetite and 1 case of worsened liver functions. In the QID group, adverse reactions were observed in 5 cases ; 4 cases of constipation and 1 case of worsened liver functions. The physicians in charge judged that there was a casual relation between the adverse reactions and the drug in one of 4 cases in the BID group and in 4 of 5 cases in the QID group. Concerning the effect of adverse reactions on continuance of the clinical trial, only in 1 case of the BID group the adverse reaction was severe enough to discontinue the trial, and in this case the administration of the drug was discotinued according to the patient's request. This 40-year-old male patient had complained of constipation before starting the administration. On the 7 th day, administration of the drug was discontinued as he complained of aggravation of constipation. After discontinuing the drug, aggravation and relief of constipation repeated and the physician judged that this symptom was not related to the administred drug.

In the QID group, serious adverse reaction developed in 1 case, but discontinuance of the drug administration was required in none of the cases.

TABLE 5. List of side-effect

\begin{tabular}{|c|c|c|c|c|c|}
\hline $\begin{array}{l}\text { Method of } \\
\text { adminis- } \\
\text { tration }\end{array}$ & $\begin{array}{l}\text { Symptoms } \\
\text { of } \\
\text { side-effect }\end{array}$ & $\operatorname{Sex}$ & $\begin{array}{l}\text { Age } \\
\text { (year) }\end{array}$ & $\begin{array}{c}\begin{array}{c}\text { Time of appearance } \\
\text { of side-effect }\end{array} \\
\begin{array}{c}\text { Administration } \\
\text { period (days) }\end{array}\end{array}$ & $\begin{array}{l}\text { Physician's } \\
\text { comment } \\
\text { on drug } \\
\text { relation }\end{array}$ \\
\hline \multirow{4}{*}{ BID } & $\begin{array}{l}\text { Constipation } \\
(+)\end{array}$ & $\mathrm{F}$ & 60 & 10 & Unknown \\
\hline & $\begin{array}{l}\text { Constipation } \\
\text { (H) }\end{array}$ & M & 40 & $\begin{array}{l}\text { Before start trial } \\
\qquad(+)\end{array}$ & No \\
\hline & $\begin{array}{l}\text { Poor appetite } \\
(\mathbb{H})\end{array}$ & $\mathrm{M}$ & 33 & 26 & Yes \\
\hline & $\begin{array}{l}\text { Worsened liver } \\
\text { dysfunction } \\
\qquad(+)\end{array}$ & $\mathrm{M}$ & 54 & 21 & Unknown \\
\hline \multirow{5}{*}{ QID } & $\begin{array}{l}\text { Constipation } \\
(+)\end{array}$ & $\mathrm{M}$ & 45 & 13 & Yes \\
\hline & $\begin{array}{l}\text { Constipation } \\
\qquad(+)\end{array}$ & $\mathrm{M}$ & 50 & 1 & Unknown \\
\hline & $\begin{array}{l}\text { Constipation } \\
(+)\end{array}$ & $\mathrm{M}$ & 68 & 3 & Yes \\
\hline & $\begin{array}{l}\text { Constipation } \\
(+)\end{array}$ & $\mathrm{M}$ & 50 & 3 & Yes \\
\hline & $\begin{array}{l}\text { Worsened liver } \\
\text { disfunction } \\
(+)\end{array}$ & M & 54 & 14 & Yes \\
\hline
\end{tabular}




\section{Effects of laboratory test results}

Laboratory tests were performed both before and after the administration period and changes in the laboratory data were assessed. The value for each parameter out of normal range was judged as abnormal. Abnormal changes were classified into 2 groups: abnormal $\rightarrow$ abnormal (aggravation) and normal $\rightarrow$ abnormal.

No significant difference in the incidence of abnormal changes was seen between the BID and the QID groups as to any of the test parameters. The data obtained for 8 parameters (WBC count, platelet count, GOT, GPT, A1-P, BUN, creatinine, and serum $\mathrm{Fe}$ level) are shown in Table 8 together with changed values in the cases which showed abnormal changes. On the other hand, the doctor found abnormal values in: WBC count in 4 cases (2 cases each for BID group and QID group), GOT in 8 cases (4 cases each for BID group and QID group), GPT in 11 cases (6 cases for BID group and 5 cases for QID group), A1-P in 1 cases (QID group), Fe in 3 cases (2 cases for BID group and 1 cases for QID group), hematocrit in 1 case (BID group) and cholesterol in 1 case (QID group).

\section{Discussion}

Although the etiology of peptic ulcer has not been fully elucidated, the theory of the balance between the aggressive and defensive factors suggested by Shay and Sun (1953) has been generally accepted.

The treatment of peptic ulcer includes bed rest, hospitalization, dietary therapy and pharmacotherapy. Among them, pharmacotherapy plays an important role and drugs to inhibit the aggressive factors such as antacids, anticholinergic drugs, antipepsin drugs and antigastrinics, drugs to enhance the deffensive factors such as drugs to protect the mucosa, circulation improving drugs and tissue metabolism activating drugs have been used to treat peptic ulcer. The basic principle of pharmacotherapy is to use these drugs in the optimal combination according to the disease entity of individual cases.

However, as Schwarz (1910) who pointed out the important role of gastric acid in development of peptic ulcer by saying "no acid, no ulcer", gastric acid is considered to be a main factor for development of ulcer. It is needless to say that the drugs which inhibit secreation of gastric acid are important for the treatment of ulcer. Cimetidine is a histamine $\mathrm{H}_{2}$ receptor antagonist different from any of the conventional antacids or anticholinergics in mode of action. It was developed to be potent in inhibition of gastric acid secreation and have less adverse reactions, and has been used in clinical practice.

In general, cimetidine is administred at $200 \mathrm{mg}$ per dose after each meal and $400 \mathrm{mg}$ at bedtime, totally $1,000 \mathrm{mg} /$ day in European countries. In the United States it is administred at $300 \mathrm{mg}$ per dose four times daily (after each meal and at bedtime), totally $1,200 \mathrm{mg}$ /day. However, it has been reported that $400 \mathrm{mg}$ 
cimetidine once in the morning was almost comparable to $100 \mathrm{mg}$ cimetidine three times daily (after each meal) as to inhibition of daytime acid secretion (Burland et al. 1980). Moreover, Blackwood and Northfield (1977) found that the administration of $400 \mathrm{mg}$ cimetidine once at bedtime could completely inhibit nocturnal gastric secretion. Based on these findings, the twice daily administration of cimetidine at $400 \mathrm{mg}$ per dose was evaluated in terms of various points such as therapeutic efficacy, pain relief efficacy, reducing the amount of antacids required and incidence of adverse reactions. As a result, the twice daily administration was found to produce clinical efficacy almost comparable to that obtained by the four times daily administration without statistically significant difference and to simple administration methods reported by Delattre et al. (1982), Eckardt et al. (1982) and Kerr (1982). The standard dosage used in Japan is $200 \mathrm{mg}$ per dose four times a day, totally $800 \mathrm{mg} /$ day as reported by Miyoshi et al. (1980). However, the present study was conducted to compare the efficacy of cimetidine for gastric ulcer between the four times daily administration at $200 \mathrm{mg}$ per dose and twice daily administration at $400 \mathrm{mg}$ per dose in a double blind manner.

Out of 139 cases of gastric ulcer initially admitted to the study, 60 cases of the BID group and 60 cases of the QID group were included in analysis. The two groups were comparable without great difference concerning the background factors except for the shape of ulcer i.e., 'circular" and 'oval', which had statistically significant difference.

The ulcer healing rate was $35.6 \%$ after 4 weeks and $82.8 \%$ after 8 weeks for the BID group, with corresponding figures for the QID group being 35.8\% and $74.1 \%$, respectively. No statistic difference in healing rate was seen between the two groups. With respect to the final global improvement in subjective and objective symptoms, no difference was observed between the two groups except for the item of postprandial epigastric pain after 2 weeks, epigastric pain on fasting after 1 and 2 weeks of treatment and nocturnal pain after 2 weeks. No differences were seen between the two groups with respect to global efficacy, incidence of side effects of laboratory test results.

In the present study, the results obtained for the BID group were slightly inferior to those for the QID group with respect to the tenderness of the epigastrium, while no difference was seen in the final global improvement in subjective and objective symptoms. Delattre et al. (1982) reported that in the treatment of gastric ulcer no difference was seen between the BID group and the QID group in relief of pain, indicating the almost similar efficacy can be expected from those two dosage regimens.

\section{References}

1) Blackwood, W.S. \& Northfield, T.C. (1977) Nocturnal gastric acid secretion, Effect of cimetidine and interaction with anticholinergics. In : Cimetidine. Proceedings of the Second International Symposium on Histamine $\mathrm{H}_{2}$ receptor Antagonists, edited by 
W.L. Burland \& M.A. Simkims, Excerpta Medica, Amsterdam-Oxford-Princeton, pp. 124-130.

2) Burland, W.L., Burnet, P.L., Hunt, R.H., Melvin, M.A., Mills, G.J., Vincenc, D. \& Milton-Thompson G.J. (1980) Comparison of the effect on 24-hour intragastric acidity of SKF 92994 and two dose regimens of cimetidine. Hepatogastroenterology, Suppl., 10, 259 .

3) Delattre, M., Prinzie, A. \& Underwood, D. (1982) The treatment of doudenal ulceration - a comparative trial of cimentidine (Tagamet) at b.i.d. ( $800 \mathrm{mg}$ daily) and at $\mathrm{q}$. i.d. (1000 mg daily) dosages. Clin. Trials $J ., 19,226-238$.

4) Eckardt, V.F., Kanzler, G., Willems, D., Feyerabend, H., Backwinkel, K.P., Hentschel, E., Schütze, K. \& Schwamberger, K. (1982) Therapie des Ulcus duodeni mit Cimetidin. Dtsch. med. Wschr., 107, 60-62.

5) Kerr, G.D. (1982) Cimetidine: Twice daily administration in duodenal ulcer -A multicentre group study. Practitioner, 226, 978-980.

6) Miyoshi, A., Ohoi, K., Sato, K., Yabana, T., Ishmori, A., Takeshi, K., Omata, S., Sajima, Y., Nakazawa, S. \& Imai, K. (1979) Effect of cimetidine, an $\mathrm{H}_{2}$-receptor antagonist, on gastric acid secretion, Part 3, Inhibition of nocturnal gastric acid secretion. Naikahokan, 26, 217-224. (Japanese)

7) Miyoshi, A., Ohoi, K., Sato, K., Yabana, T., Ishimori, A., Kawamura, T., Matsuo, Y., Kitamura, T., Takeuchi, T., Marzuyama, M., Miwa, M., Okabe, H., Saigenji, K., Omata, S., Sajima, Y., Nakazawa, S., Imai, K., Uchino, H., Moriga, M., Kawai, K., Misaki, F., Kori, D., Kita, S., Kishi, S., Kitamura, Y. \& Hayakawa, K. (1980) Early clinical trial cimetidine in gastric and duodenal ulcers. Shinryo to Shinyaku, 17, 1265-1272. (Japanese)

8) Schwarz, K. (1910) Ueber penetrierende Magen und jejunalgeschwüre. Bruns' Beitr. Klin. Chir., 67, 96-128.

9) Shay, H. \& Sun, D.C.H. (1953) Etiology and pathology of gastric and duodenal ulcer. In: Gastroenterology, vol. I, edited by H.C. Bockus, Saunders Co., PhiladelphiaLondon-Toronto, pp. 420-465. 